\title{
Air ventilation impacts of the "wall effect" resulting from the alignment of high-rise buildings
}

\author{
Yim, S. H. L. ${ }^{a}$, Fung, J. C. H. ${ }^{b}$, Lau, A. K. H. ${ }^{c}$ and Kot, S. C. ${ }^{d}$ \\ ${ }^{a}$ Atmospheric, Marine and Coastal Environment Program, The Hong Kong University of Science and Technology, Hong Kong \\ ${ }^{\mathrm{b}}$ Department of Mathematics, The Hong Kong University of Science and Technology, Hong Kong \\ ${ }^{\mathrm{c}}$ Institute for the Environment, The Hong Kong University of Science and Technology, Hong Kong \\ ${ }^{\mathrm{d}}$ Department of Mechanical Engineering, The Hong Kong University of Science and Technology, Hong Kong
}

\section{Summary}

The objective of this study is to investigate the air ventilation impacts of the so called "wall effect" caused by the alignment of high-rise buildings in complex building clusters. The research method employs the numerical algorithm of computational fluid dynamics (CFD) to simulate the steady-state wind field in a typical Hong Kong urban setting and investigate pollutant dispersion inside the street canyon utilizing a pollutant transport model. The validation study on our model settings was accomplished by comparing the simulation wind field around a single building block to wind tunnel data. The results revealed that our model simulation is fairly close to the wind tunnel measurements. In this paper, a typical dense building distribution in Hong Kong with 2 incident wind directions $\left(0^{\circ}\right.$ and $\left.22.5^{\circ}\right)$ is studied. Two performance indicators are used to quantify the air ventilation impacts, namely the velocity ratio $\left(V R_{w}\right)$ and the retention time $\left(T_{r}\right)$ of the dispersion of pollutants at the street level. We found that the velocity ratio at $2 \mathrm{~m}$ above ground was reduced $40 \%$ and retention time of pollutants increased $80 \%$ inside the street canyon when high-rise buildings with 4 times height of the street canyon are aligned as a "wall" at the upstream. While this reduction of air ventilation was anticipated, the magnitude is significant and this result clearly has important implications for building and urban planning.

\section{Introduction}

Land prices in a commercial city increase rapidly year to year. (HKRVD, 2009) shows the rent price of the office grade A in the commercial sections in Hong Kong. For example, for the Central (location is shown in Figure 1), the rent price increases 33\% from 2005 to 2007. To cope with increasing land costs property developers often increase their building height. This fuels the increasing trend towards taller and taller 
buildings. For example, the Shanghai World Finance Center and Taipei 101 which are around $488 \mathrm{~m}$, are signs of an increasing trend towards mega-towers around the world. In Hong Kong, thousands of buildings stand over urban areas, such as Mong Kok, Causeway Bay and Central (see Figure 1). The spectacular backdrop of Hong Kong with dazzling neon cityscapes shown in Figure 2 reveals that thousands of high-rise buildings stand over Hong Kong.

Figure 1 shows the frontal area density over Hong Kong. The frontal area is often used in computing the drag force on solid objects immersed in fluids (Bottema, 1996; Bottema, 1997; Bottema et al., 1998). The frontal area density, a measure of the frontal area per unit horizontal area per unit height increment, has been used by researchers in the plant canopy and urban canopy communities to help quantify the drag force as a function of height. The drag force approach allows one to compute the area-averaged wind profile within the canopy. The frontal area density $\left(a_{f}(z)\right)$ is defined as:

$$
a_{f}(z, \theta)=\frac{A(\theta)_{\operatorname{proj}(\Delta z)}}{A_{T} \Delta z}
$$

where $A(\theta)_{\operatorname{proj}(\Delta z)}$ is the area of building surfaces projected into the plane normal to the approaching wind direction for a specified height increment $(\Delta z), \theta$ is the wind direction angle, and $A_{T}$ is the total plan area of the study site. For a specified wind direction, the integral of $a_{f}(z)$ over the canopy height equates to $\lambda_{f}$ which is defined as $\lambda_{f}=A_{f} / A_{d}$ where $A_{f}$ is the frontal area of each obstacle exposed to the wind and $A_{d}$ is the underlying surface area of an obstacle (total area divdied by the number of obstacles).

The frontal area density is weighted by the proportions of 16 wind directions which are provided from hour-by-hour wind fields of the three entire years wind field simulations over Hong Kong, please see (Yim, 2009) for details. From Figure 1, we found that high frontal area density (in red) is at the high-dense urban area and along the coastal line. That's means the deficit of air ventilation in the urban area, since the air flow is blocked by the buildings along the coastal line. 
Table 1 shows the statistic of different building heights in Hong Kong. It shows that $52 \%$ of buildings in Hong Kong are around 8 floors high $(20 \mathrm{~m})$ while around $9 \%$ of the buildings are higher than $80 \mathrm{~m}$ which is 4 times of the typical building height. This number is increasing in recent years. In addition, in order to tackle the astonishing land costs, the property developers often increase the building height and stand the high-rise buildings along the coastal line which is also shown in Figure 1. It found that, the density of building along the coast is higher than the inland. Since capturing an admirable seascape would enhance the value of the properties, developers would eager to stand their buildings as close to the coast as possible. These buildings can block the sea breeze "fresh air" which is important for the air ventilation and the pollutant dispersion in the street canyon.

Cluster of buildings as a "wall” blocks air flow into these areas and hence reduce air ventilation. This causes the so called "wall effect”. Stagnant air causes discomfort to pedestrians and pollutants accumulate at street level. Pedestrians are exposed to such adverse situations everyday and this may directly affect their health. The data analysis done by the Hong Kong Environmental Protection Department (HKEPD) about the Maximum Annual Pollutant Concentrations and Objectives in 2007 found that the concentration of pollutants measured at the three roadside stations (Mong Kok, Central and Causeway Bay), such as $\mathrm{NO}_{2}$, TSP and RSP, are very relatively high comparing with other general stations (open area) and even exceed to the annual Air Quality Objective (AQO) (Non-compliance of annual Air Quality Objective (AQO) values. Due to the people always expose to such districts, this fact is thought to contribute to respiratory diseases becoming extremely common in Hong Kong. (Lam et al., 2006) shows that the proportionate mortality (as percentage of total deaths) due to the diseases of the respiratory system are 17.7\%, 16.9\%, 18.3\% in 2003, 2004 and 2005 respectively. Therefore the fresh air ventilation of a city area should be a key planning issue and the government should pay particular attention to this when examining and approving construction proposals. Thus, the wind field and the ability of pollutant dispersion in the street level should be investigated further.

Canyon flow analysis has been originally discussed by (Oke, 1988) and flow across canyons of different height $(h)$ to width $(w)$ aspect ratio $(h / w)$ is categorised into three regimes namely isolated roughness flow (IRF: $h / w>0.5$ ), wake interference flow (WIF: $h / w=1.2-5.0$ ) and skimming flow (SF: $h / w=0-1.2$ ). In numerical analyses, canyon airflows are commonly discussed (Huang et al., 2000) and (Sini et al., 1995) and many research findings have attained the three regimes mentioned by (Oke, 1988). However, the effect of pollutant dispersion has not been quantified. (Cheng et al., 2001) 
demonstrated the capability of using CFD model (FLUENT) to reproduce the accurate simulations of the bluff body flow and transport of urban pollution. They considered the road source along the streets with different aspect ratios of street width to the building height. However, Cheng focuses on the numerical performance of the model rather than further investigate the air ventilation and dispersion rate within the street canyon. (Garcia Sagrado et al., 2002) studied the numerical and experimental modelling of pollutant dispersion in a street canyon. It has been observed that the re-circulating bubble inside the street canyon blocks the pollutants from going out of the street, helping it to stay trapped in the corners of the street. Therefore, in the cases where this re-circulating bubble in the interior of the canyon is present, higher concentration is found inside the street. However, this study was only simulated in 2-dimensional geometry that may not fully represent the complex situation in the street canyon. In addition, pollutant dispersion rate and the influence of the "wall-effect" on the urban area have not been fully investigated.

This paper is to investigate the air ventilation and pollutant dispersion rate in the street canyon when 6 high-rise buildings are situated upstream of the flow. Two factors, velocity ratio $\left(V R_{w}\right)$ and retention time $\left(T_{r}\right)$, will be measured to quantify the influences of "wall effect" of the frontal high-rise buildings.

\section{Model validation}

\subsection{Wind tunnel experiment}

In the validation study, the simulation results are compared with the wind tunnel data. The wind tunnel experiment is described in detail by (Ishihara and Hibi, 1998) and therefore only the important details are presented in this paper. In the experiment, a square building model with scale ratio of 2:1:1 (height : width : depth) is placed within a turbulent boundary layer, (see the Figure 3 ) and the wind profiles approaches a power law profile with index 0.27 from the upstream. A split film probe was used to measure the average wind velocity in each direction of 3-dimensional space and the standard deviation of fluctuating wind velocities. The dimensional of the model building was $0.08 \mathrm{~m}$ in width and length $(b)$ and $0.16 \mathrm{~m}$ in height $(h)$. The turbulence statistics were measured at the centerline of a vertical cross-section as shown in Figure 4(a) and on horizontal planes at $1 / 16(\mathrm{z} / \mathrm{b}=0.125)$ and $10 / 16(\mathrm{z} / \mathrm{b}=1.25)$ of the building height as shown in Figure 4(b). 66 and 60 measurement points in vertical and in horizontal directions are set to measure the average wind velocity in each direction of 3-dimensional space and the standard deviation of fluctuating wind velocities. The 
locations of the measurement points in the wind tunnel test are shown in Figure 4. The measurement point data will be compared with our simulation results.

\subsection{CFD model configuration}

In the validation simulation, a square shaped building with scale ratio of 2:1:1 (height $(h)$ : width $(b)$ : depth $(b))$ is located in the computational domain in our CFD model. The domain size is designed according to the CFD guidelines (Franke, 2004; Tominaga et al., 2008). Both of them also recommend that the lateral and the top boundary should be set $5 H$ or more away from the building, where $H$ is the height of the target building (Mochida et al., 2002; Shirasawa et al., 2003). The outflow boundary should be set at least $10 H$ behind the building. The lateral size of the computational domain should extend about $5 \mathrm{H}$ from the outer edges of the target building. Based on the recommendations, the building in this validation case is located $5 h$ away from the inflow boundary and $15 h$ away from the outflow boundary. It is also $5 h$ away from the left and right boundary and $5 h$ away from the ceiling. The geometry is shown in Figure 5(a-b). The meshes are generated denser at the building surroundings and become less dense away from the building. Such grid distribution is to re-solve the wind fields around the building more details and reduce the computational time for the coarse resolution at the less-concerned region. Second order discretization scheme for the pressure calculation and second order upwind discretization scheme for the momentum, turbulent kinetic energy and turbulent dissipation rate calculations are utilized. The smooth surface wall condition is adopted for the two side boundaries and upper boundary of the simulation domain. The wall boundary condition with roughness length $z_{0}=1.8 \times 10^{-4} \mathrm{~m}$ is set on the ground of the domain. The inflow boundary condition is interpolated from the experimental approaching flow with $\varepsilon=C_{\mu}^{1 / 2} k \cdot d U / d z$. The profile is shown in Figure 9(a-b). The zero gradient condition is at the outflow boundary. Realizable k- $\varepsilon$ turbulent model are utilized. The summary of the model setting is shown in Table 3.

Figure 6 compares the experimental and calculated scalar wind velocity on vertical cross-section along the centerline. The scalar wind velocity (wind speed) is normalized according to the wind speed at the same height when there is no building (i.e. wind speed increase ratio). If it is limited to the region where the wind speed has increased (region where wind speed increase ratio is 1.0 or more), which is important in the evaluation of the pedestrian wind environment (Yoshie et al., 2007), it is predicted within an accuracy of approximately $\pm 10 \%$. However, in the weak wind region behind the building, the wind speed ratio is evaluated lower in the calculation 
than in the experiment. The result is consistent with that of (Yoshie et al., 2007).

The distribution of average wind velocity $u$ and $w$ on the vertical cross-section along the centerline of the building is shown in Figure 7(a) and Figure 7(b). In the figures, the longitudinal dotted lines represent the positions of the measuring lines in the experiment. Wind velocities are plotted transversely using this as the origin. (Positive values are plotted on the right side of the measuring line, and negative values on the left side.) The calculated values agree fairly well with the experimental values.

The distributions of $u$ and $v$ on the horizontal plane $(z / b=1.25)$ are shown in Figure 7(c) and Figure 7(d), respectively. The calculated values and the experimental values agree relatively well except that the calculated $u$ is slightly higher than the experimental value beside the building wall at position line $x / b=-0.25$ and $x / b=0$.

The distributions of $u$ and $v$ on the horizontal plane $(z / b=0.125)$ near the ground surface are shown in Figure 7(e) and Figure 7(f), respectively. The simulated values and the experimental values agree relatively well except that the simulated $u$ is lower than the experimental value in the wake region. In Figure $7(\mathrm{e})$, near the ground surface of measurement line $x / b=1.25$ (the third measuring line from the right), $u$ is negative in the experiment and reverse flow occurs. This is reproduced in the simulation. On the lower portion of measuring line $x / b=3.25$ (the rightmost measuring line), the simulated $u$ is lower than the experimental value. Also the reattachment length behind the building is slightly longer in the simulation. The result is also consistent with that of (Yoshie et al., 2007).

Our CFD model is validated by the wind tunnel experience and shows that the model settings are robust to reproduce the realistic wind field. Then the air ventilation impacts as influenced by the alignment of high-rise buildings to the downstream street canyon will be investigated and presented in section 3 .

\section{CFD model configuration}

In order to investigate the air ventilation impacts as influenced by the alignment of high-rise buildings to the downstream street canyon, a $147.6 \mathrm{H} \times 88.5 \mathrm{H} \times 32 \mathrm{H}$ computational domain is set in the CFD simulation where $H$ is $20 \mathrm{~m}$ (a typical height of the low-rise buildings in Hong Kong) (see Figure 1). A 6x3 low-rise buildings with height $H$ form a regular set of parallel street canyon with a constant aspect ratio of street 
width to the building height equal to about 1.3 which is defined as skimming flow by (Oke, 1988). 6 high-rise buildings with height $H_{v a r}$ is located $5 H$ away at the upstream where $H_{v a r}$ varies in different cases and the values of $H_{v a r}$ are shown in Table 2. The building geometry is shown in Figure 5(c-d) and Figure 8. The denser grid structure is surrounding the study area while the grids become less dense to the boundary.

Two incident wind directions are investigated - Study A $\left(\theta_{1}\right): \theta_{1}=0^{\circ}$ incident wind direction and Study B $\left(\theta_{2}\right): \theta_{2}=22.5^{\circ}$ incident wind direction. Four cases in $\theta_{1}$ and $\theta_{2}$ will be simulated. Control case represents a situation before 6 high-rise buildings $(4 H)$ being constructed upstream in front of a group of low-rise buildings. Other three cases are considered to investigate how the situation changes with different heights of the high-rise buildings being constructed. Case $4 H$ represents 6 high-rise buildings (each are $4 H$ height) built in front of street canyon while case $2 H$ and case $H$ represents 6 high-rise buildings with 2 times height of and same height of the low-rise buildings respectively.

To investigate the local wind availability around the study area, an appropriate wind profile can be provided by numerical models such as MM5/CALMET system or wind tunnel experiment. (Yim et al., 2007) coupled MM5 and CALMET to simulate wind fields over complex terrain area (Guangdong, Pearl River Delta and Hong Kong) in high resolutions with land-sea breeze considerations which provides an appropriate wind profile and representative wind rose over the study area. For wind tunnel experience, (HKPD, 2008) used a 1:2000 scale topographical study of Tsim Sha Tsui (a typical urban area in Hong Kong), included the surrounding area up to a distance of approximately $10 \mathrm{~km}$ from the study area, to determine the effects of local topography and the surrounding urban environment on mean wind speed and turbulence intensity. The topographical study results were combined with a statistical model of the Hong Kong wind climate, based on measurements of non-typhoon winds taken by Hong Kong Observatory at Waglan Island (a relatively open station to represent the ambient wind of Hong Kong) during the period of 1953 - 2000 inclusive, to determine wind roses corresponding to annual mean wind speeds at the measurement positions. A miniature pressure probe was used to take measurements of wind speed and turbulence intensity profile.

In this study, the wind and turbulent intensity profiles (see Figure 9(c-d)) are provided by the wind tunnel experience (HKPD, 2008). The boundary conditions are same as that of the validation study while the roughness of the ground is $0.5 \mathrm{~m}$ which corresponds to residential area. The Realizable $k-\varepsilon$ turbulent model is utilized. Once 
the steady state wind fields (scaled residual is dropped 4 orders of magnitude following the recommendation of (Franke, 2006)) are simulated, the velocity ratio can then be calculated. Then the wind fields will be utilized as an initial condition for the unsteady dispersion simulation. The time step is 0.25 s which satisfies the CFL condition and the simulation is processed until the retention time reached (definition of retention time will be discussion later). The summary of the simulation conditions is shown in Table 3, for details, please refer to (Yim, 2009).

In this CFD study, an averaging volume $D$ (with height $H$ ) is defined in which the volume average wind speed and retention time for the pollutant dispersion within this volume are calculated. The location of $D$ is shown in Figure 8 with dashed line. In order to quantify the air ventilation impact of the "wall effect" of the high-rise buildings, the velocity ratio at $2 \mathrm{~m}$ above ground (pedestrian level), average velocity ratio and retention time in $D$ are computed in this study. 


\section{Air ventilation indicators}

The key purpose of an indicator is to investigate the wind environment information, and in what form, is needed to guide design and planning so as to achieve a better wind penetration into and hence, air ventilation of the city especially at the pedestrian level. The focus of the methodology is to introduce two parameters to quantify the air ventilation impact of the alignment of high-rise buildings to the downstream street canyon. These parameters provide information to indicate and to allow better layout design of developments and planning of the urban fabric.

\section{Velocity Ratio $\left(V R_{w}\right)$}

Wind Velocity Ratio $\left(V R_{w}\right)$ is measured and defined as:

$$
V R_{w}=V_{p} / V_{\infty}
$$

$V_{\infty}$ is the wind velocity at the top of the wind boundary layer not affected by the ground roughness, buildings and local site features (typically assumed to be a certain height above the roof tops of the city center and is site dependent). The wind speed at $450 \mathrm{~m}$ of the incident profile is defined as $V_{\infty} . V_{p}$ is the average wind velocity at the pedestrian level (2m above ground) after taking into account the effects of buildings. The Wind Velocity Ratio $\left(V R_{w}\right)$ indicates how much of the wind availability of a location could be experienced by pedestrians on ground taking into account the surrounding buildings. As $V R_{w}$ is solely affected by the buildings of the location, it is a simple indicator to reflect the wind environment of the study site. The higher the value of $V R_{w}$, the lesser the impact of buildings on wind availability.

\section{Retention time $\left(T_{r}\right)$}

A field study of tracer dispersion from an urban street canyon in (De Paul and Shieh, 1986) was conducted in order to obtain measurements of pollutant retention time and resulting concentrations within the canyon. The retention time, representing the time for pollutant released at street level to reach $e^{-1}$ (36.7\%) of its original value, were computed from the history of tracer gas concentration following removal of a controlled tracer release. In order to investigate the dispersion rate in the street canyon, the retention time $T_{r}$ of pollutants in $D$ is measured in the study. 


\section{Numerical simulation on wind speed}

Figure 10(a-d) show the $V R_{w}$ at the pedestrian level (2m above ground) in $\theta_{1}$. Obviously, the $V R_{w}$ in the downstream area is higher in control case than other three cases. Without the upstream buildings blocking the incoming flow, the approaching wind flow can directly flow into the street canyon hence the $V R_{w}$ in the downstream area is higher in control case.

Figure 11(a-c) shows the percentage difference of the $V R_{w}$ at the pedestrian level by comparing the control case with (a) case $H$; (b) case $2 H$; (c) case $4 H$ calculated by the formula:

$$
\frac{V R_{w_{c}}-V R_{w_{H}}}{V R_{w_{c}}} \times 100 \%
$$

where $V R_{w_{c}}$ is the velocity ratio in control case and $V R_{w_{H}}$ is the velocity ratio in case $H$, case $2 H$ or case $4 H$. It shows that the $V R_{w}$ at the leeward side of the frontal buildings drops more than $50 \%$. Although the channeling effect to increase the velocity ratio is observed between two front buildings in other three cases, it is not able to compensate the serious $V R_{w}$ reduction at the downstream. In road 1 (see Figure 8), the $V R_{w}$ is only reduced by within $30 \%$ in case $H$ and case $2 H$. However, the reduction can get worse to around $60 \%$ in case $4 H$. Such reduction is also observed in road 2 (see Figure 11(c)), and even to the further downstream.

In order to understand the air ventilation within the street canyon, column average (up to $20 \mathrm{~m}$ ) of velocity ratio for every grid point $\left(V_{c}\right)$ in domain $D$ is calculated. Figure 10(e-h) represent the $V_{c}$ in $\theta_{1}$. Similar to the situation at $2 \mathrm{~m}$ above ground, the $V_{c}$ behind the front buildings drops significantly. Figure 11(d-f) shows the percentage difference of the $V_{c}$ by comparing the control case with (d) case $H$; (e) case $2 H$; (f) case $4 H$. As shown in the figures, the $V_{c}$ reduction increases when the height of the front buildings increases. The width of the low $V_{c}$ zone also increases when the height of the front buildings increases. In case $H$, the low $V_{c}$ zone is narrow. However it becomes wider in the case $2 \mathrm{H}$ and the case $4 \mathrm{H}$. It demonstrates that the external free stream above the urban canyon is seriously blocked by the front buildings. In the case $H$ and the case $2 H$, there are some regions in road 1 where the $V_{c}$ increases or decreases. Nevertheless, in the case $4 H$, the $V_{c}$ is reduced everywhere and the decrease can be up to $80 \%$ drop. 
The velocity ratios in $D$ are volume averaged and the results are shown in Table 4 . It shows that the velocity ratio reduction is small when the front buildings are built as same height as the street canyon. It is only less than $1 \%$ reduction in $V R_{w}$ compared with that of the control case. However, when the height of the front buildings is changed to 2 times of the height of building cluster, the velocity ratios reduced by almost 30\%. It is because not only the lower level wind flow is blocked, but also the upper layer wind flow is not able to enter the building cluster directly. This situation becomes more serious when the height of front buildings changes to 4 times of the building cluster. The velocity ratio reduction can be as much as $40 \%$. Such large portion of the prevailing wind is blocked and it causes poor ventilation inside the street canyon and an unacceptable pedestrian comfort.

Figure 13 shows the velocity distribution of different cases in Domain $D$ and at $2 \mathrm{~m}$ above ground in Study A $\left(\theta_{1}\right)$. It shows that when the height of the frontal buildings increase, the frequency of the low wind situation also increases which would make the situation worse for the air ventilation point of view.

Figure 12(a-d) show the $V R_{w}$ at the pedestrian level $(z=2 \mathrm{~m})$ in $\theta_{2}$ which represents the pedestrian comfort in the street. Although, there is also a channeling effect between the frontal high buildings, the air flow is not able to penetrate into the street canyon. It is obvious that the $V R_{w}$, in the case $4 H$, is seriously reduced at the downwind area. In addition, the width of the low $V R_{w}$ zone becomes wider while the height of the front building increases. Figure 12(e-h) show the $V_{c}$ in $\theta_{2}$ show the $V R_{w}$ reduction percentage in $\theta_{2}$. It shows that more serious reduction in $V R_{w}$ while the height of frontal building increases. The $V_{c}$ in $D$ is also shown in Table $4.16 \%$ reduction of average velocity ratio in $D$ is computed in the case $H$ while $24 \%$ and $35 \%$ reduction in the case $2 \mathrm{H}$ and $4 \mathrm{H}$ respectively. Such large reduction in velocity ratio reveals that the pedestrian comfort becomes worse while the height of the front building increases. 


\section{Dispersion of passive pollutant}

Beside the velocity ratio $\left(V R_{w}\right)$, the retention time $T_{r}$ is also another important parameter to measure the air ventilation in the canyon cavity. It is no doubt that the $T_{r}$ directly reflects the air quality in the street level. When the $T_{r}$ is high, that means more time is required for the pollutants to disperse out of street canyon. In order to understand the influence of the front high-rise building constructions on the $T_{r}$ in $D$, a group of road sources is set within $D$. The locations of the road sources as represented in line sources are shown in Figure 8 (solid lines). These road sources instantaneously release at time $\mathrm{t}=0 \mathrm{~s}$ and how these pollutants disperse with the street canyon is traced numerically. The subsequence concentration and hence $T_{r}$ within $D$ would then be computed. In the study, the $T_{r}$ in different cases will be compared to reflect the pollutants dispersion rate within $D$.

Figure 14 shows the time series of the percentage of pollutants remaining in $D$ in $\theta_{1}$. The concentration rises at the first 30s because of the pollutants accumulation effect in $D$. When the air flow is approaching to the street canyon, the dispersion rate in the wake region of the buildings is rather weak while windward is relatively strong. The pollutants at the two side roads are starting to disperse into $D$ and so the percentage of concentration in $D$ increases. We can see that the duration time for this accumulation effect is longer while the height of the frontal buildings increases.

After the initial accumulation period, the pollutants concentration drops as the time. It shows that the dispersion rate of control case is quite high while case $4 H$ is the worst compared with all cases. The $T_{r}$ for each case is shown in Table 4. Longer $T_{r}$ means it requires a longer time to disperse the pollutant to $e^{-1}$ (36.7\%) of the original concentrations in $D$. In the table, it shows that the $T_{r}$ of control case is shortest, which is about 194s. It is an expected result, since the approaching wind penetrates to $D$ directly and it favours dispersion. Although the $V_{c}$ in $D$ in case $H$ is reduced less than $1 \%$, the $T_{r}$ increases almost $10 \%$ compared with control case. It is because the front buildings cause the wind field to circulate within the low building cluster which fuels an accumulation effect of the pollutants. This circulating zone traps the pollutants and it hinders to disperse the pollutants out of $D$. This situation becomes worse in case $2 H$ and $4 H$. The $T_{r}$ increases nearly $45 \%$ and $81 \%$ in the case $2 H$ and the case $4 H$ respectively compared with control case.

Figure 15 shows the time series of the percentage of pollutants remaining in $D$ in $\theta_{2}$. There is also an accumulation period in the first 30s which is similar to the $\theta_{1}$. 
After the accumulation period, the pollutants concentration also drops as the time. The dispersion rate in control case is the highest while $4 H$ is the lowest. Figure 16 shows that the percentage change of the $T_{r}$ in (c) $\theta_{1}$ and (d) $\theta_{2}$. It reveals that the percentage change of $T_{r}$ increases while the height of frontal building increases. The $T_{r}$ increases $13 \%, 27 \%$ and $41 \%$ in the case $H, 2 H$ and $4 H$ respectively as shown in Table 6. The increase of $T_{r}$ means that it requires a longer time to disperse the pollutant to $e^{-1}(36.7 \%)$ of the original concentrations in $D$. It is found that the case $4 H$ is still the worst case in term of the retention time though the upwind direction has \pm 22.5 degree variation. 


\section{Summary}

In the study, two different approaching wind directions $\left(0^{\circ}\right.$ and $\left.22.5^{\circ}\right)$ are considered for the effectiveness of the air ventilation and the influences of different heights of the frontal building are studied. The velocity ratio $\left(V R_{w}\right)$ at $2 \mathrm{~m}$ above ground (pedestrian level), column average velocity ratio ( $V_{c}$ - up to first $20 \mathrm{~m}$ above ground) and retention time $\left(t_{r}\right)$ of pollutants in $D$ are measured to quantify the air ventilation impact caused by the "wall effect" buildings. It shows that the velocity ratio reduction can be almost $30 \%$ and $40 \%$ if $2 \mathrm{H}$ and $4 \mathrm{H}$ high-rise buildings are located at the upstream of street canyon respectively. It can also cause serious impacts on the pollutant dispersion. The increase of the retention time of pollutants within the street canyon can be $45 \%$ and $80 \%$ if $2 \mathrm{H}$ and $4 \mathrm{H}$ respectively. When the wind direction changes to $22.5^{\circ}$ degree to the buildings, the retention time of pollutants also increases nearly $30 \%$ and $40 \%$ in the case $2 H$ and $4 H$ respectively. It concluded that the alignment of high-rise buildings located at the upstream of the city, especially for the buildings along the coastal line, causes a vital "wall effect" to the city not only on the air ventilation but also the pollutants dispersion rate. Therefore, the government should pay more attention on the influence of the "wall effect" in the city planning. 
Bottema, M., 1996. Roughness parameters over regular rough surfaces; experimental requirements and model validation. Journal of Wind Engineering and Industrial Aerodynamics Volumes 64, pp. 249-265.

Bottema, M., 1997. Urban roughness modelling in relation to pollutant dispersion. Atmospheric Environment 31-18, pp. 3059-3075.

Bottema, M. and Mestaye, P.G., 1998. Urban roughness mapping - validation techniques and some first results, Journal of Wind Engineering and Industrial Aerodynamics Volumes 74-76, 1, Pages 163-173

Cheng, H.C. and Robert N. Meroney, 2001. Numerical and physical modeling of bluff body flow and dispersion in urban street canyons, Journal of Wind Engineering and Industrial Aerodynamics, 89, Issues 14-15, Pages 1325-1334.

CUHK, 2008. Urban Climatic Map and Standards for Wind Environment - Feasibility Study Working Paper 1A: Draft Urban Climatic Analysis Map.

De Paul and Shieh, C.M., 1986. A tracer study of dispersion in an urban street canyon, Atmospheric Environment 20, pp. 455-459.

Franke, J., 2006. Recommendations of the COST action C14 on the use of CFD in predicting pedestrian wind environment. In: The Fourth International Symposium on Computational Wind Engineering, Yokohama, Japan.

Garcia Sagrado, A.P., van Beeck, J., Rambaud, P. and Olivari, D., 2002. Numerical and 
experimental modelling of pollutant dispersion in a street canyon, Journal of Wind Engineering and Industrial Aerodynamics 90, pp. 321-339.

HKPD, 2008. Air Ventilation Assessment for the Nominated Study Area at Mong Kok, Causeway Bay, Tsun Wan, Tsim Sha Tsui, Sheung Wan, Urban Climatic Map and Standards for Wind Environment - Feasibility Study, Technical Report for Planning Department, The Government of Hong Kong Special Administrative Region, Pages $1-250$.

HKPD, 2008. Site Wind Availability Report - Mong Kok, Causeway Bay, Tsun Wan, Tsim Sha Tsui, Sheung Wan, Urban Climatic Map and Standards for Wind Environment - Feasibility Study, Technical Report for Planning Department, The Government of Hong Kong Special Administrative Region, Pages 1-305.

HKRVD, 2009. Private Office - 1984-2007 Rental and Price Indices for Grade A Office in Core Districts, Rating and Valuation Department, The government of the Hong Kong Special Administrative Region.

Available at:

http://www.rvd.gov.hk/en/doc/statistics/his_data_10.pdf

Huang, H., Akutsu, Y., Arai, M., Tamura, M., 2000. A two dimensional air quality modeling an urban street canyon: evaluation and sensitivity analysis. Atmospheric Environment 34, 689-698.

Ishihara, T. and Hibi, K., 1998. "Turbulent measurements of the flow field around a 
high-rise building”, J. of Wind Eng., Japan, No.76, 55-64. (in Japanese)

Lam, J. S. L., Lau, A.K.H., and Fung, J.C.H., 2006. Application of refined land-use categories for high resolution meso-scale atmospheric modeling, Boundary Layer Meteorol., 119, 263 - 288, doi:10.1007/ s10546-005-9027-3.

Murakami, S. and Mochida, 1988. A., 3-D Numerical simulation of airflow around a cube model by means of the $k-\varepsilon$ model, J. Wind Eng. Ind. Aerodynamics 31, pp. 283-303.

Oke, T.R., 1988. Street design and urban canopy layer climate, Energy and Buildings 11, pp. 103-113.

Sini, J.F., Anquetin, S., Mestayer, P.G.., 1995. Pollutant dispersion and thermal effects in urban street canyons. Atmospheric Environment 30 (15), 2659-2677.

Yim, S.H.L., J.C.H. Fung, A.K.H. Lau, and S.C. Kot, 2007. Developing a high-resolution wind map for a complex terrain with a coupled MM5/CALMET system, J. Geophys. Res. VOL. 112, D05106, doi:10.1029/2006JD007752.

Yim, S.H.L., 2009. “Modelling on mesoscale and microscale meteorology (MMM) in complex terrain and building geometry”, Thesis (Ph.D.) AMCE 2009 Yim, The Hong Kong University of Science and Technology. 
Bottema, M., 1996. Roughness parameters over regular rough surfaces; experimental requirements and model validation. Journal of Wind Engineering and Industrial Aerodynamics Volumes 64, pp. 249-265.

Bottema, M., 1997. Urban roughness modelling in relation to pollutant dispersion. Atmospheric Environment 31-18, pp. 3059-3075.

Bottema, M. and Mestaye, P.G., 1998. Urban roughness mapping - validation techniques and some first results, Journal of Wind Engineering and Industrial Aerodynamics Volumes 74-76, 1, Pages 163-173

Cheng, H.C. and Robert N. Meroney, 2001. Numerical and physical modeling of bluff body flow and dispersion in urban street canyons, Journal of Wind Engineering and Industrial Aerodynamics, 89, Issues 14-15, Pages 1325-1334.

CUHK, 2008. Urban Climatic Map and Standards for Wind Environment - Feasibility Study Working Paper 1A: Draft Urban Climatic Analysis Map.

De Paul and Shieh, C.M., 1986. A tracer study of dispersion in an urban street canyon, Atmospheric Environment 20, pp. 455-459.

Franke, J., 2006. Recommendations of the COST action C14 on the use of CFD in predicting pedestrian wind environment. In: The Fourth International Symposium on Computational Wind Engineering, Yokohama, Japan.

Garcia Sagrado, A.P., van Beeck, J., Rambaud, P. and Olivari, D., 2002. Numerical and 
experimental modelling of pollutant dispersion in a street canyon, Journal of Wind Engineering and Industrial Aerodynamics 90, pp. 321-339.

HKPD, 2008. Air Ventilation Assessment for the Nominated Study Area at Mong Kok, Causeway Bay, Tsun Wan, Tsim Sha Tsui, Sheung Wan, Urban Climatic Map and Standards for Wind Environment - Feasibility Study, Technical Report for Planning Department, The Government of Hong Kong Special Administrative Region, Pages $1-250$.

HKPD, 2008. Site Wind Availability Report - Mong Kok, Causeway Bay, Tsun Wan, Tsim Sha Tsui, Sheung Wan, Urban Climatic Map and Standards for Wind Environment - Feasibility Study, Technical Report for Planning Department, The Government of Hong Kong Special Administrative Region, Pages 1-305.

HKRVD, 2009. Private Office - 1984-2007 Rental and Price Indices for Grade A Office in Core Districts, Rating and Valuation Department, The government of the Hong Kong Special Administrative Region.

Available at:

http://www.rvd.gov.hk/en/doc/statistics/his_data_10.pdf

Huang, H., Akutsu, Y., Arai, M., Tamura, M., 2000. A two dimensional air quality modeling an urban street canyon: evaluation and sensitivity analysis. Atmospheric Environment 34, 689-698.

Ishihara, T. and Hibi, K., 1998. "Turbulent measurements of the flow field around a 
high-rise building”, J. of Wind Eng., Japan, No.76, 55-64. (in Japanese)

Lam, J. S. L., Lau, A.K.H., and Fung, J.C.H., 2006. Application of refined land-use categories for high resolution meso-scale atmospheric modeling, Boundary Layer Meteorol., 119, 263 - 288, doi:10.1007/ s10546-005-9027-3.

Murakami, S. and Mochida, 1988. A., 3-D Numerical simulation of airflow around a cube model by means of the $k-\varepsilon$ model, J. Wind Eng. Ind. Aerodynamics 31, pp. 283-303.

Oke, T.R., 1988. Street design and urban canopy layer climate, Energy and Buildings 11, pp. 103-113.

Sini, J.F., Anquetin, S., Mestayer, P.G.., 1995. Pollutant dispersion and thermal effects in urban street canyons. Atmospheric Environment 30 (15), 2659-2677.

Yim, S.H.L., J.C.H. Fung, A.K.H. Lau, and S.C. Kot, 2007. Developing a high-resolution wind map for a complex terrain with a coupled MM5/CALMET system, J. Geophys. Res. VOL. 112, D05106, doi:10.1029/2006JD007752.

Yim, S.H.L., 2009. “Modelling on mesoscale and microscale meteorology (MMM) in complex terrain and building geometry”, Thesis (Ph.D.) AMCE 2009 Yim, The Hong Kong University of Science and Technology. 


\begin{tabular}{|c|c|c|c|c|}
\hline Building Height Range (m) & $0-20$ & $20-40$ & $40-80$ & above 80 \\
\hline Percentage (\%) & 52.4 & 20.6 & 18.0 & 9.0 \\
\hline
\end{tabular}

Table 1 The statistic of building height distribution over Hong Kong. 


\begin{tabular}{|c|c|}
\hline Case name & $H_{\text {var (m) }}$ \\
\hline Control case & 0 \\
\hline Case $H$ & 20 \\
\hline Case $2 H$ & 40 \\
\hline Case $4 H$ & 80 \\
\hline
\end{tabular}

Table 2 The height of the front buildings in different cases. 


\begin{tabular}{|c|c|}
\hline \multirow{2}{*}{ Scheme for advection term } & $\begin{array}{c}\text { Second Order for Pressure; } \\
\text { Second Order Upwind Scheme for } \\
\text { Momentum, Turbulent Kinetic Energy, } \\
\text { Turbulent Dissipation rate }\end{array}$ \\
\hline Outflow boundary condition & Zero gradient condition \\
\hline Inflow boundary condition & Please refer to Figure 9 \\
\hline
\end{tabular}

Table 3 The configuration of the model in the study cases 


\begin{tabular}{|c|c|c|c|c|c|c|c|c|c|c|c|c|c|c|}
\hline & \multicolumn{10}{|c|}{} & \multicolumn{3}{c|}{$\begin{array}{c}\text { Percentage } \\
\text { difference (\%) } \\
\text { with control } \\
\text { case }\end{array}$} & \multicolumn{8}{c|}{$\begin{array}{c}\text { Percentage } \\
\text { Retention time (s) } \\
\text { difference (\%) } \\
\text { with control } \\
\text { case }\end{array}$} \\
\hline Case & control & $H$ & $2 H$ & $4 H$ & $H$ & $2 H$ & $4 H$ & control & $H$ & $2 H$ & $4 H$ & $H$ & $2 H$ & $4 H$ \\
\hline $0^{\circ}$ & 1.0 & 1.0 & 0.7 & 0.6 & 0.1 & 28.7 & 37.1 & 193.8 & 212.5 & 281.3 & 350.0 & 9.7 & 45.1 & 80.7 \\
\hline $22.5^{\circ}$ & 0.9 & 0.8 & 0.7 & 0.6 & 16.1 & 23.7 & 34.6 & 186.5 & 210.0 & 236.8 & 262.0 & 12.6 & 27.0 & 40.5 \\
\hline
\end{tabular}

Table 4 The average wind speed in the averaging region and the retention time in each case and percentage difference in the averaging region compared with the control case. 


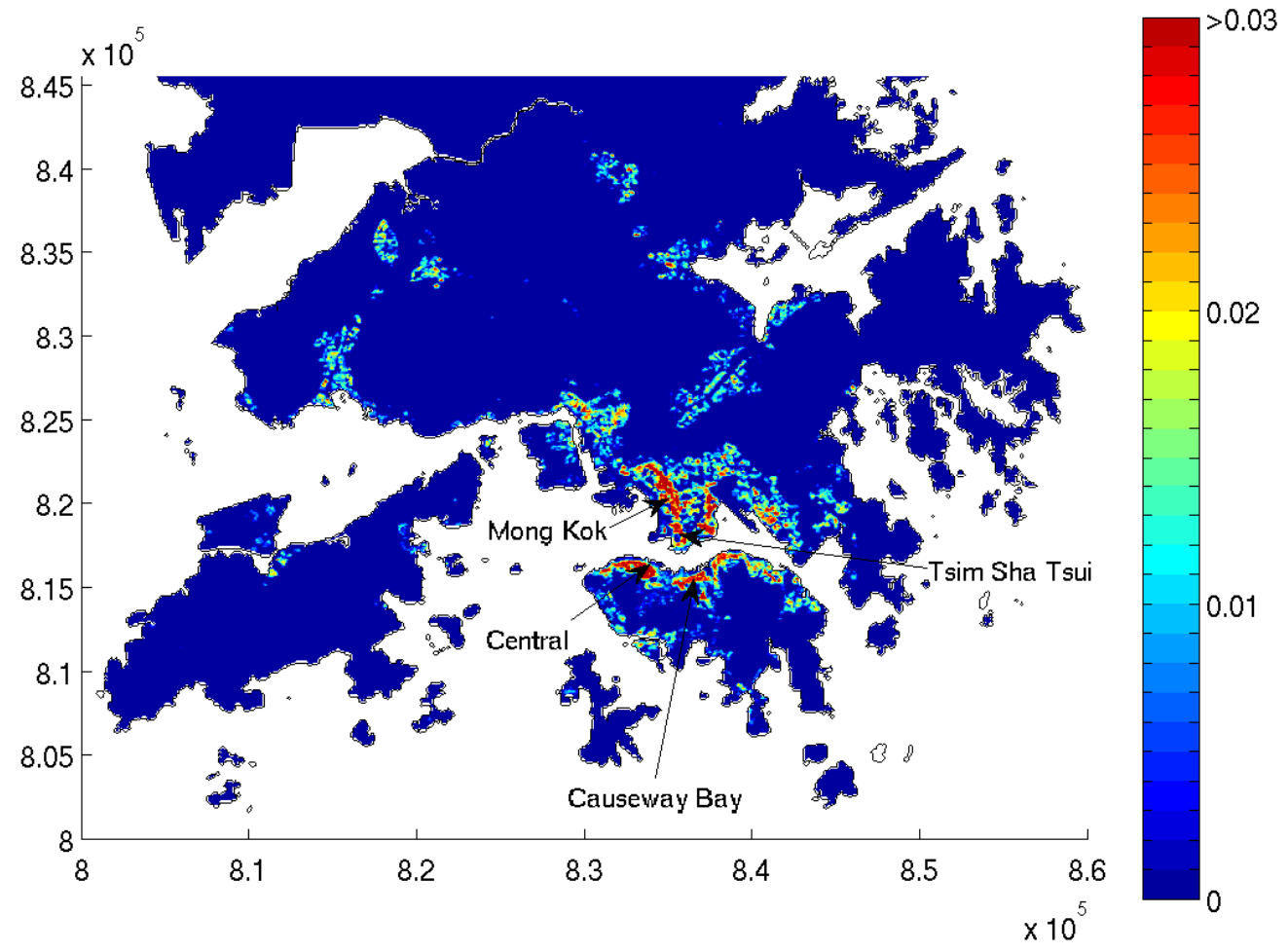

Figure 1 Frontal area density (reference) at 20m above ground over Hong Kong. 


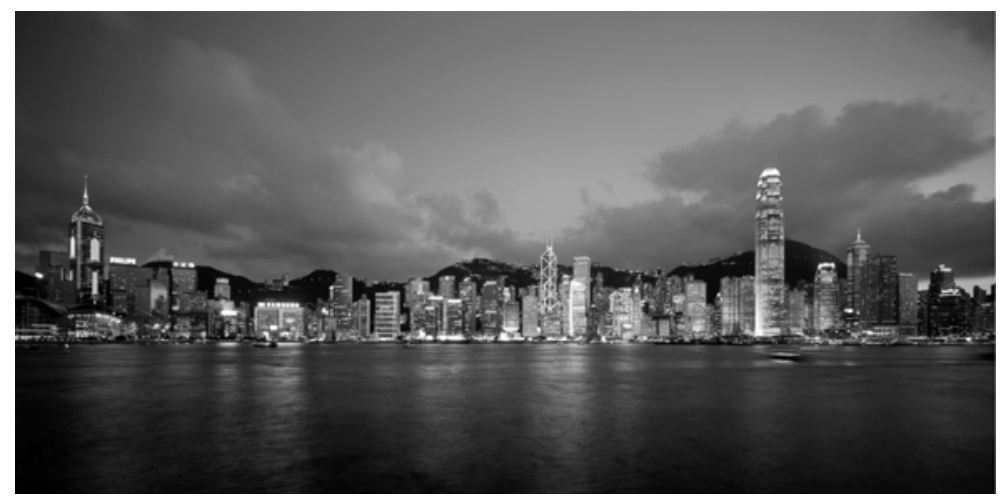

Figure 2 The seascape of Victoria Harbour. It is provided by Hong Kong Tourism Board. 


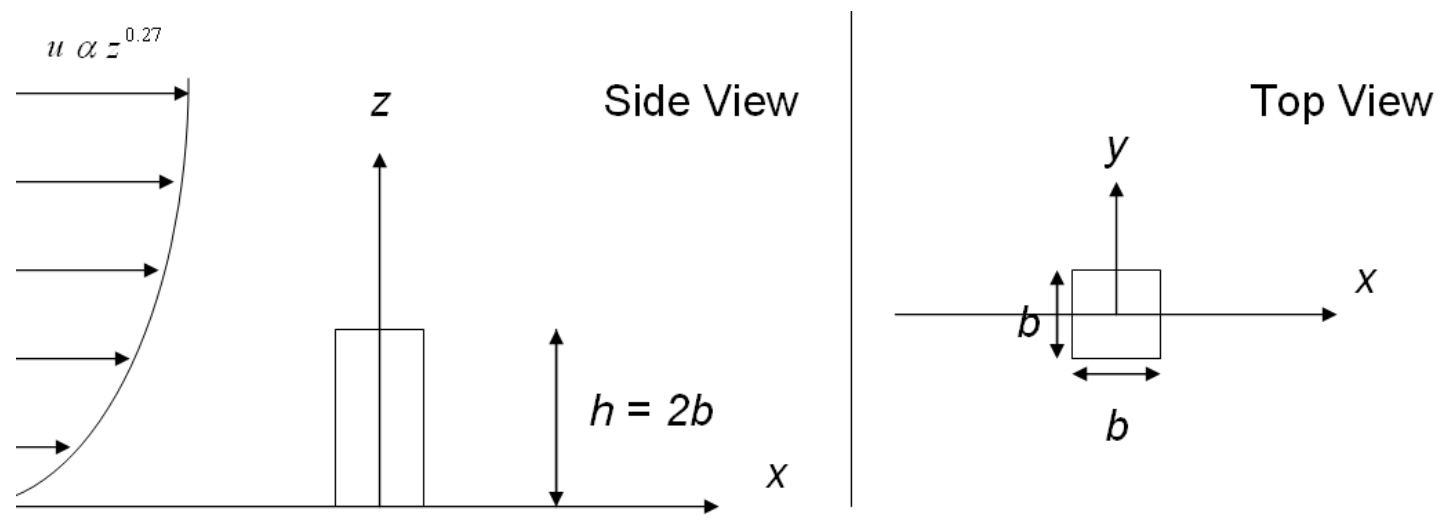

Figure 3 Configuration of experiment model and approaching wind speed profile. 
(a) Side view

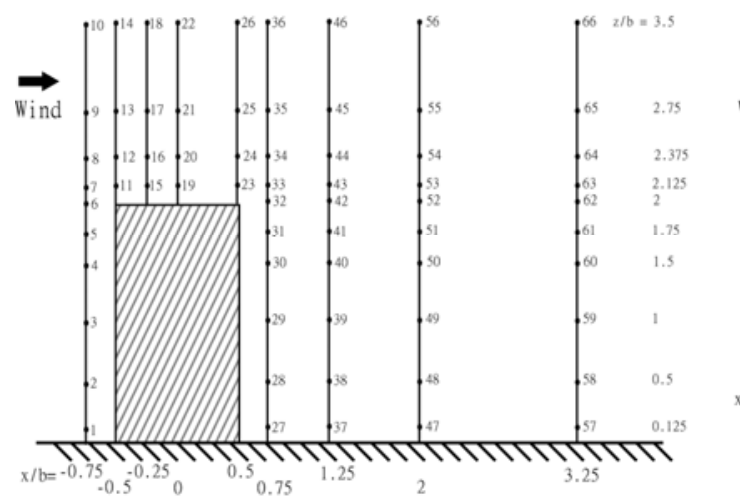

(b) Top view

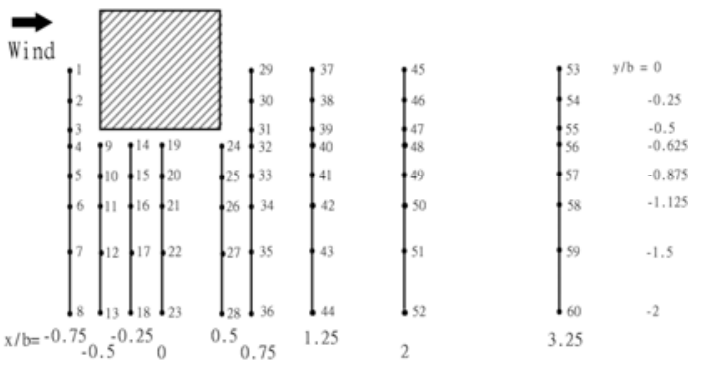

Figure 4 The measurement points in the wind tunnel test at (a) the centerline on a vertical cross-section and (b) on horizontal planes at $1 / 16(z / b=0.125)$ and $10 / 16(z / b=1.25)$ of the building height. 

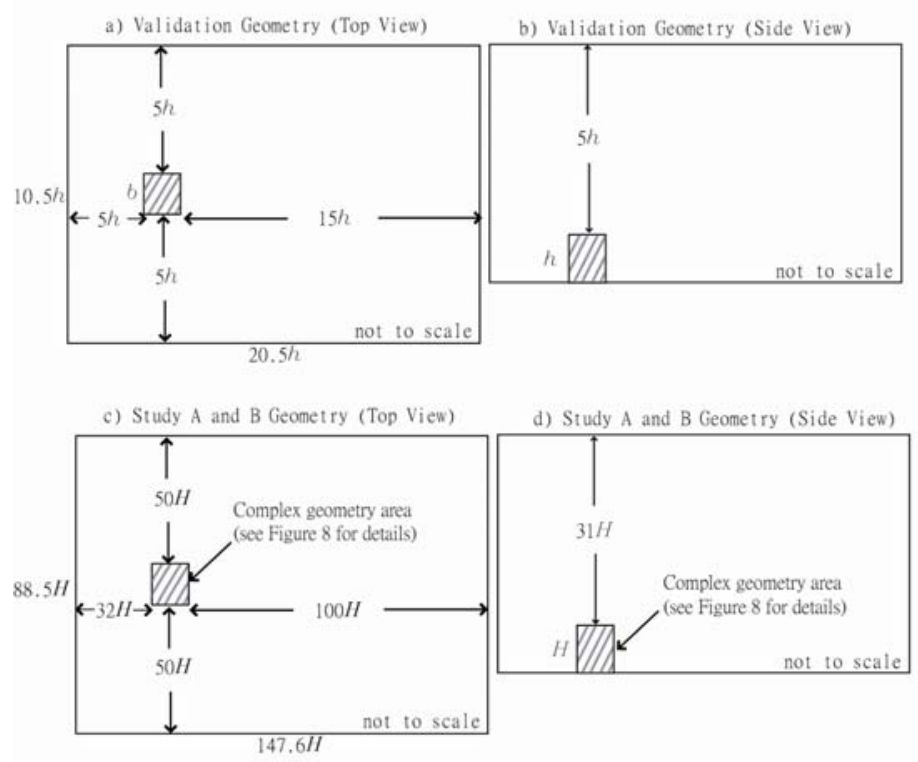

Figure 5 Validation case geometry by (a) top view and (b) Side view. Study $\mathrm{A}\left(\theta_{1}\right)$ and $\mathrm{B}\left(\theta_{2}\right)$ geometry by (c) top view and (d) Side view 


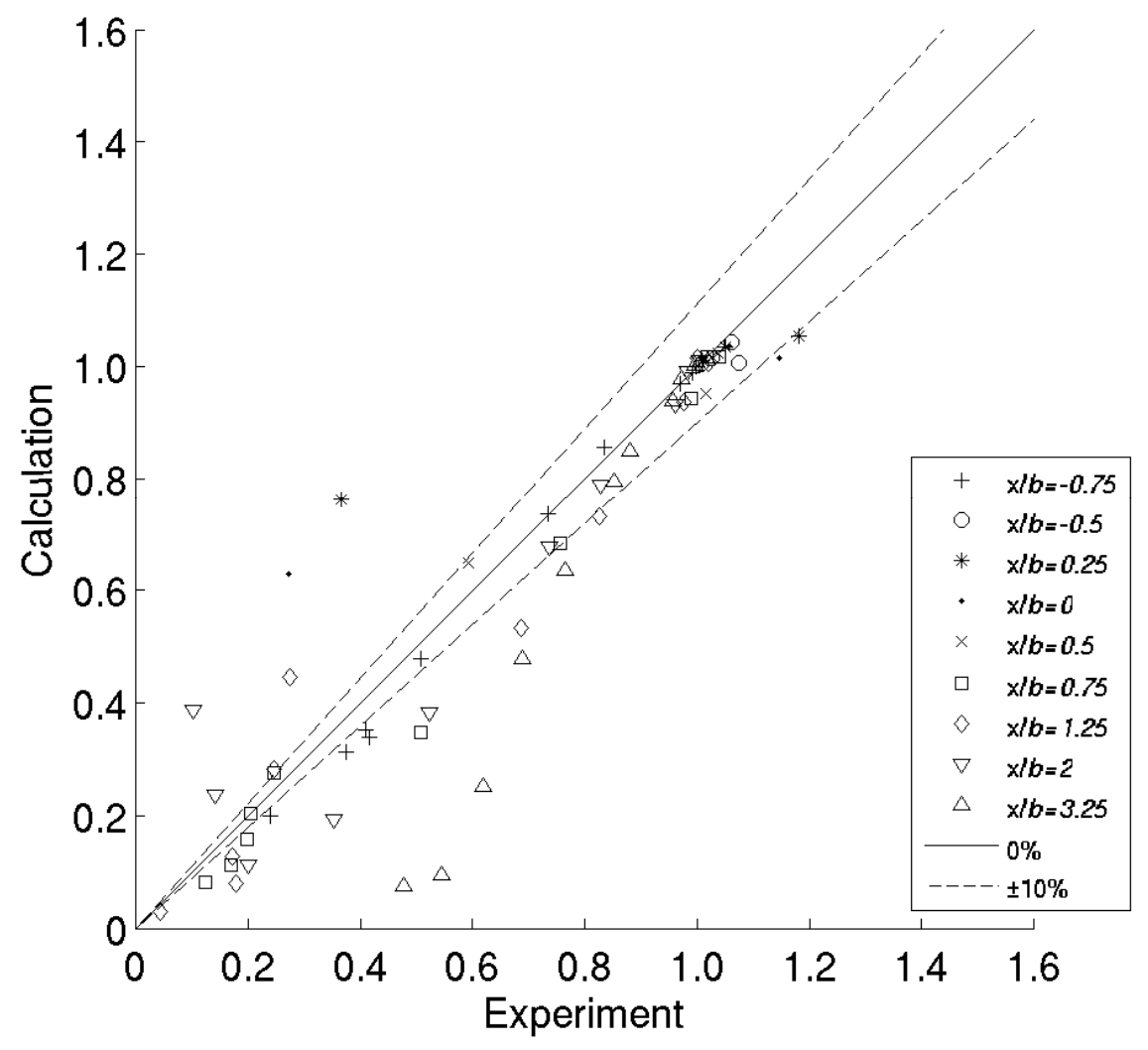

Figure 6 Comparison between the wind tunnel data and the simulation results (Vertical cross section along the centerline of the building). 

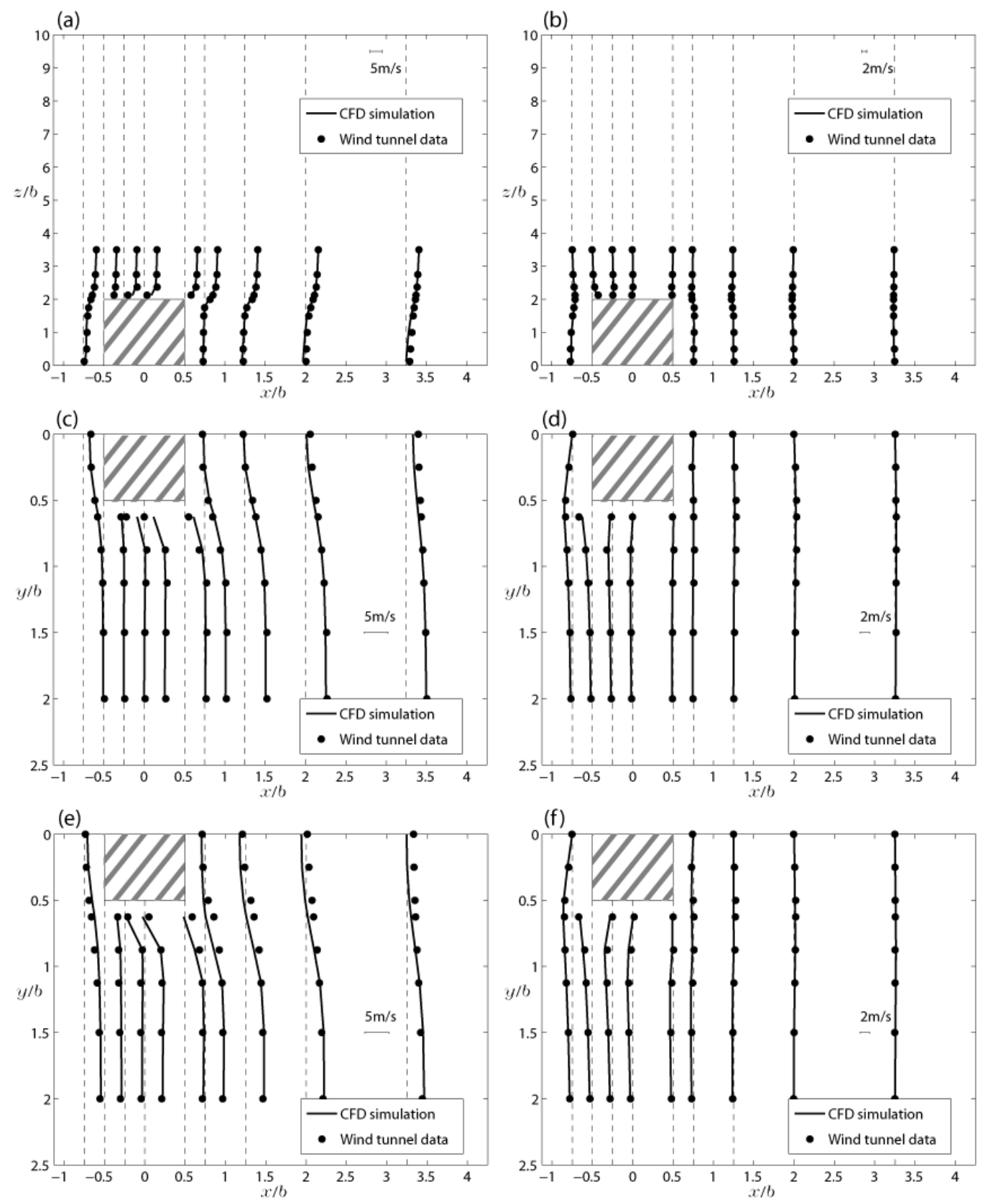

Figure 7 Comparison between the wind tunnel data with the simulation results by RKE. Vertical cross section along the centerline of the building on (a) $u$ and (b) $w$; On horizontal plane at $z=1.25 b$ on (c) $u$ and (d) $v$; On horizontal plane at $z=0.125 b$ on (e) $u$ and (f) $v$. 


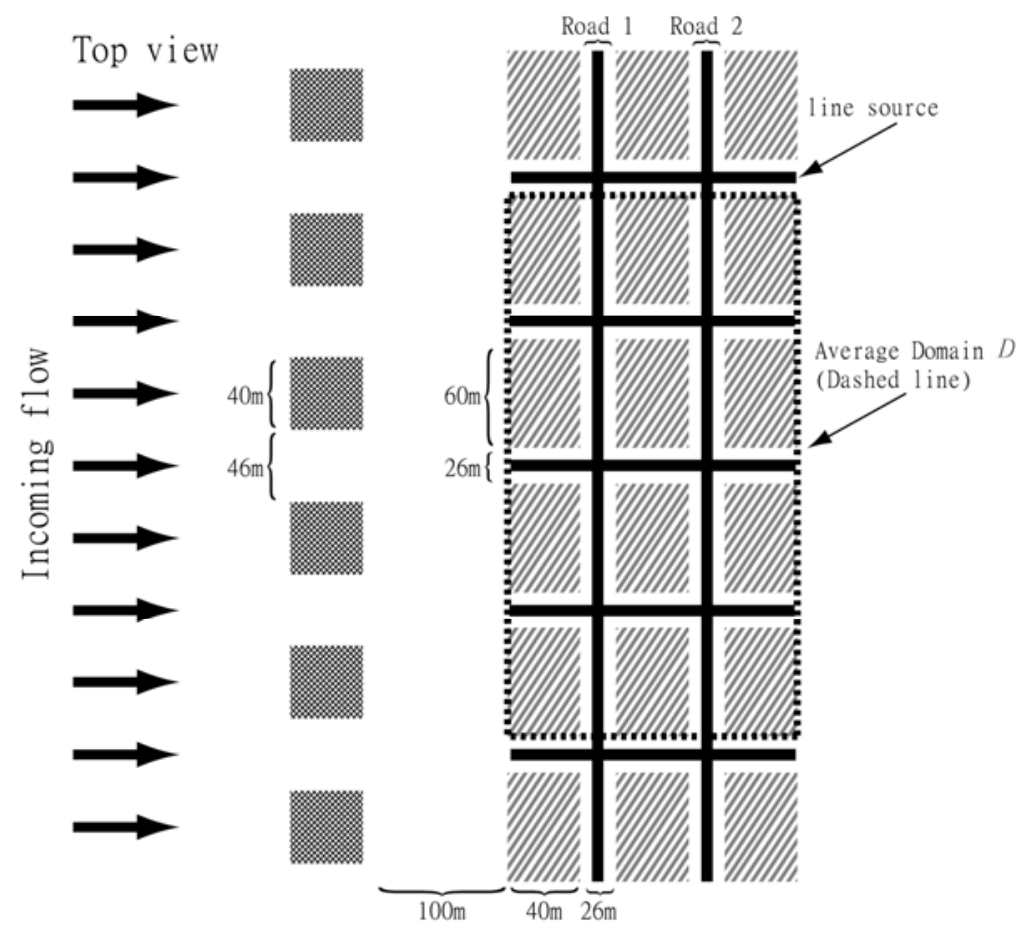

Figure 8 The top view of the building geometry. The black arrows represent the wind flow direction and the dashed line represents the averaging region $D$ for the average wind speed and the retention time calculation. 

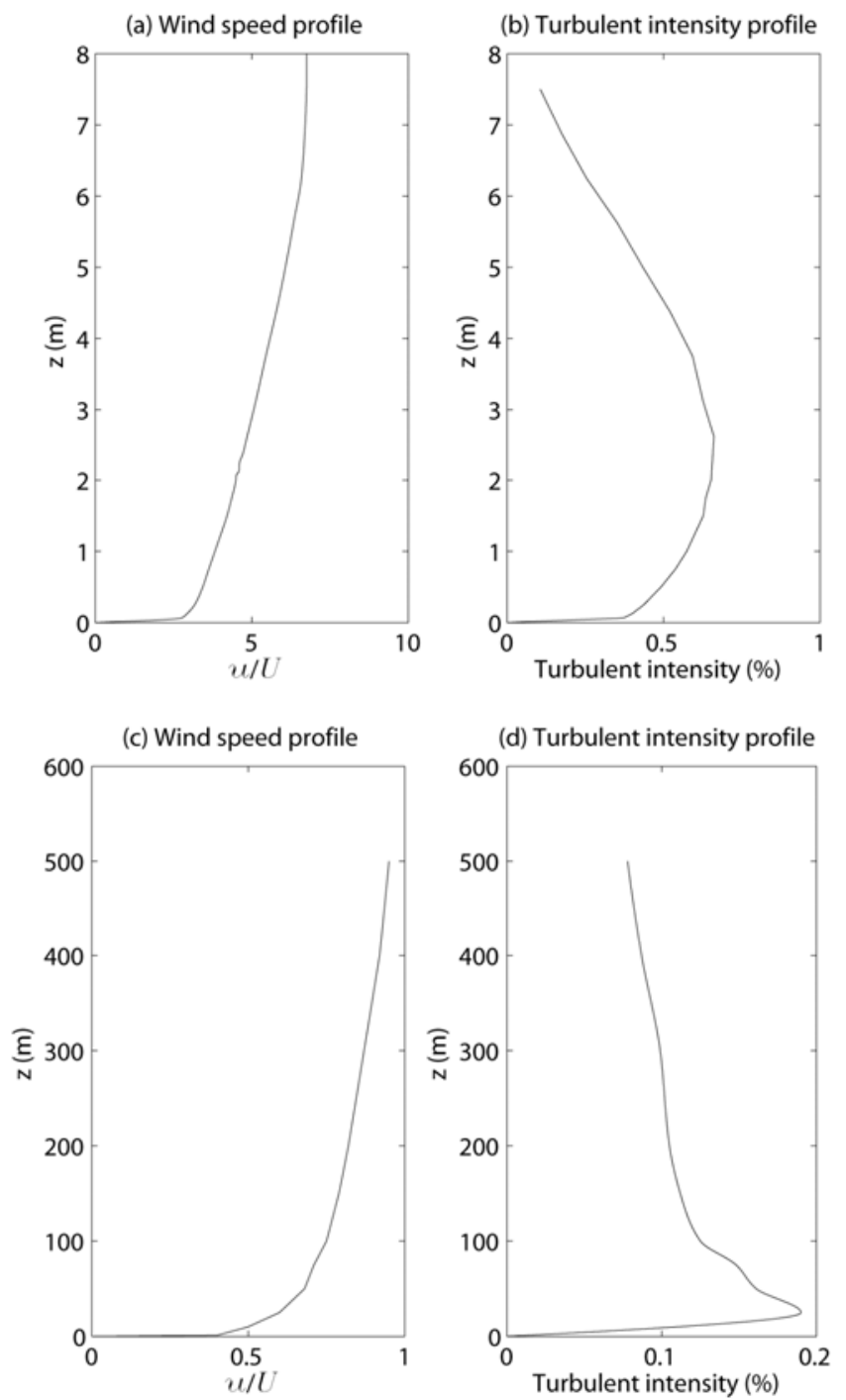

Figure 9 Vertical profile of the (a) normalized wind speed and the (b) turbulent intensity (\%) capturing in wind tunnel test in validation case. Vertical profile of the (c) normalized wind speed and the (d) turbulent intensity (\%) capturing in wind tunnel test in validation case. 

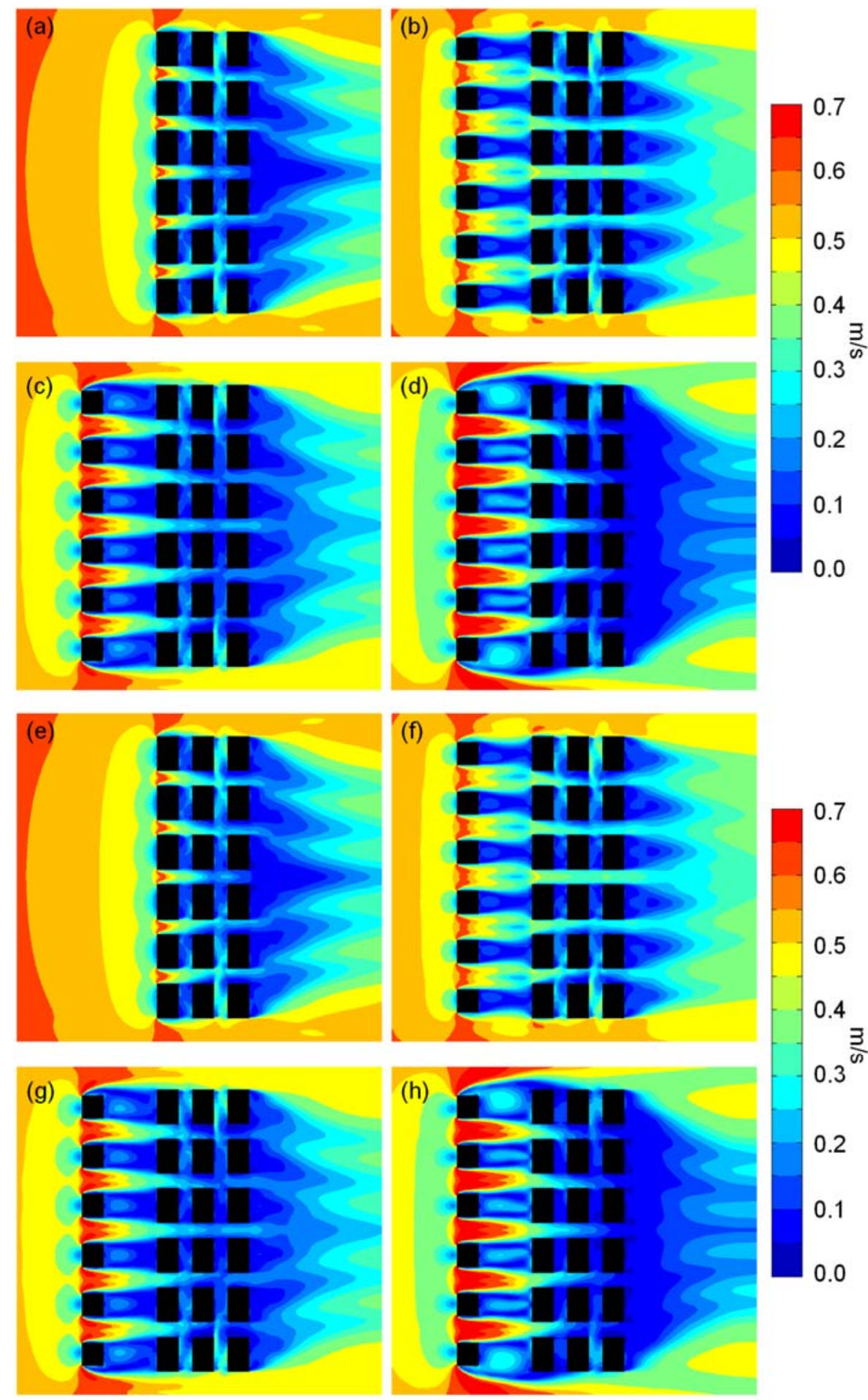

Figure 10 Velocity ratio $V R_{w}$ at pedestrian level (2m above ground) in (a) control case, (b) case $H$, (c) case $2 H$ and (d) case $4 H$ and column average (up to 20m) $V_{c}$ in (e) control case, (f) case $H$, (g) case $2 H$ and (h) case $4 H$ in Study A $\left(\theta_{1}\right)$. 

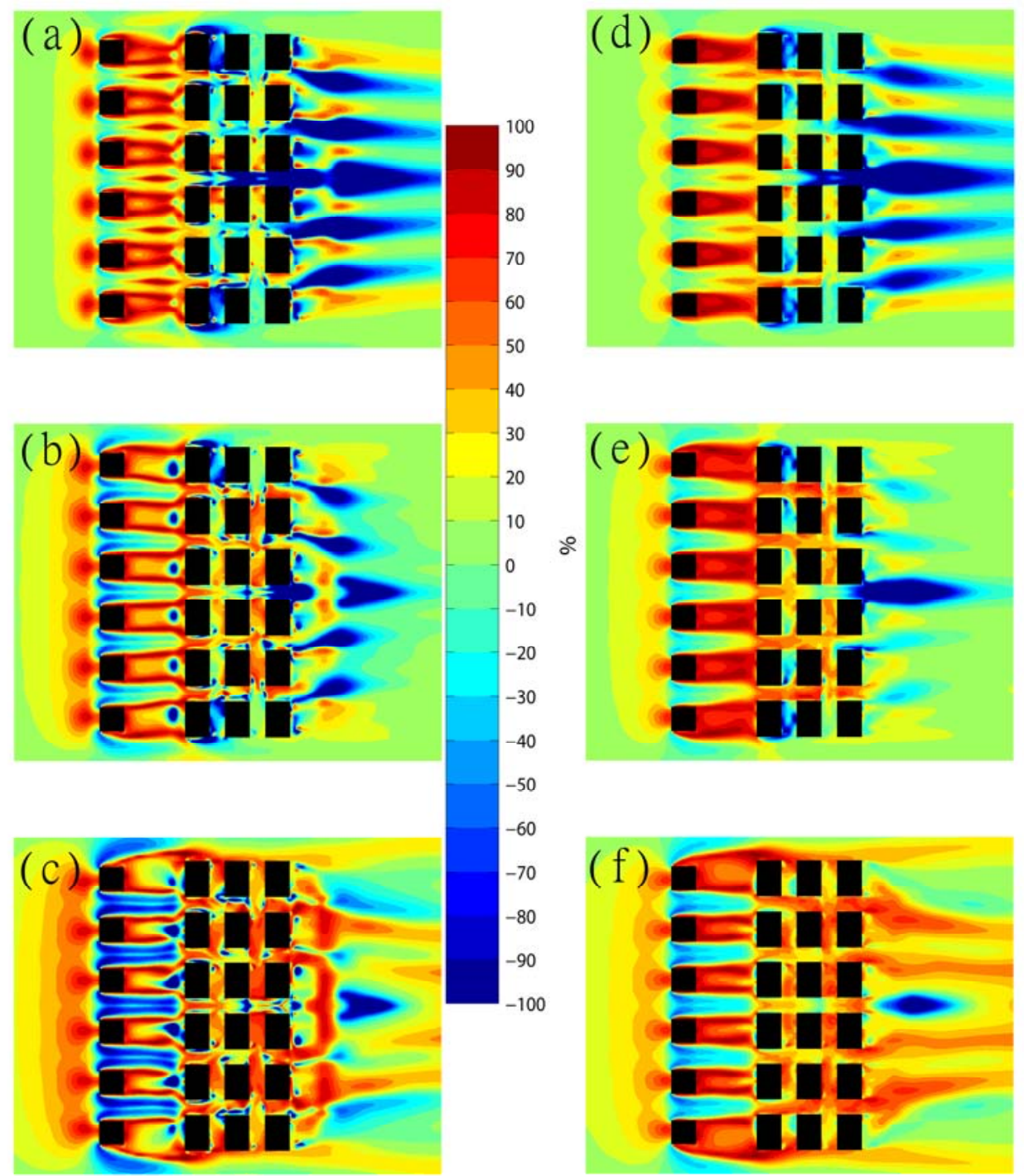

Figure 11 The percentage different of wind speed at $2 \mathrm{~m}$ (a-c) and column average up to first 20m above ground (d-f) in Study A ( $\theta_{1}$ ). (a and d) control case vs case $H$; (b and e) control case vs case $2 H$; (c and f) control case vs case $4 H$. Red color represents the decrease of wind speed while blue represents the increase of wind speed. 

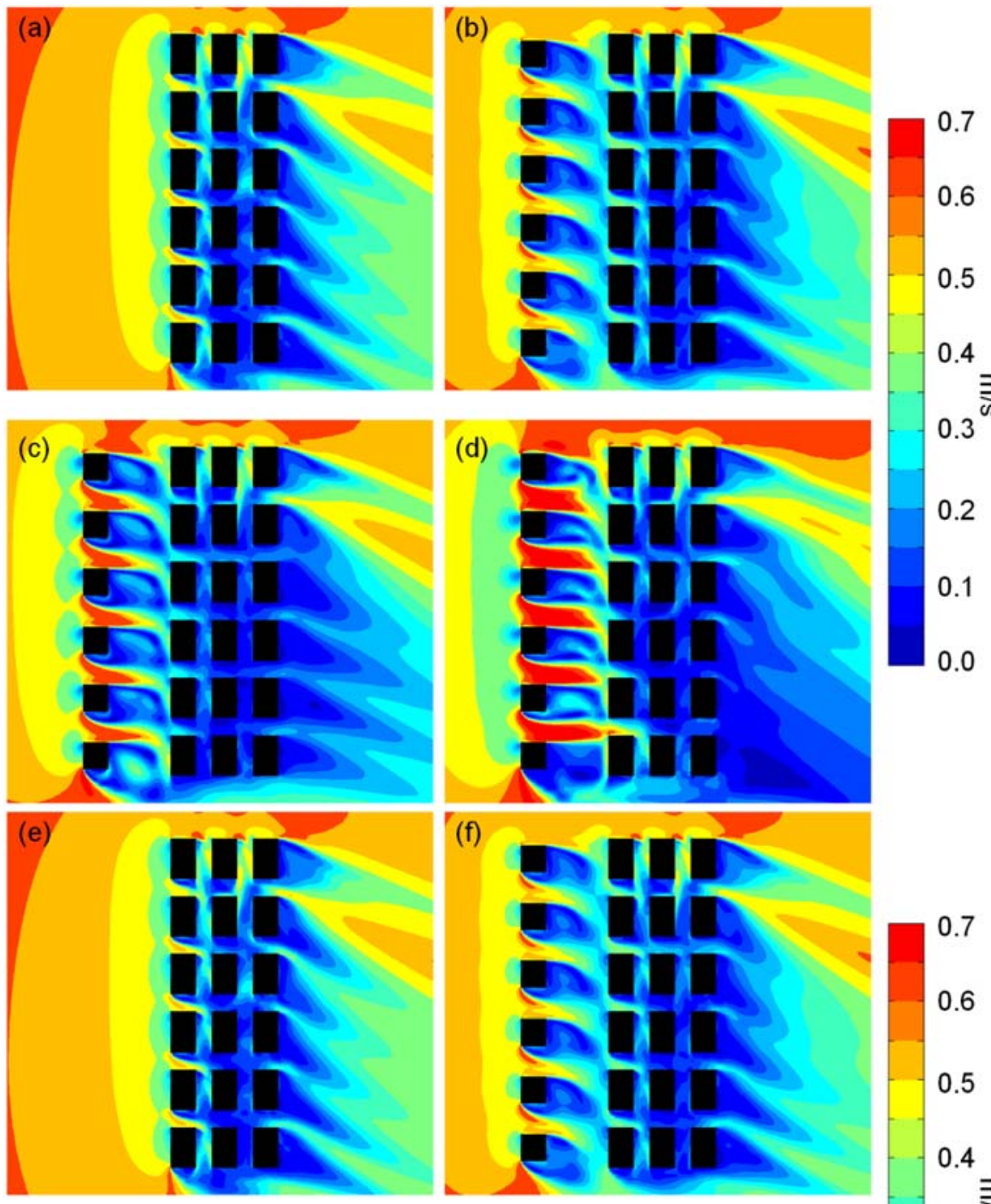

(g)

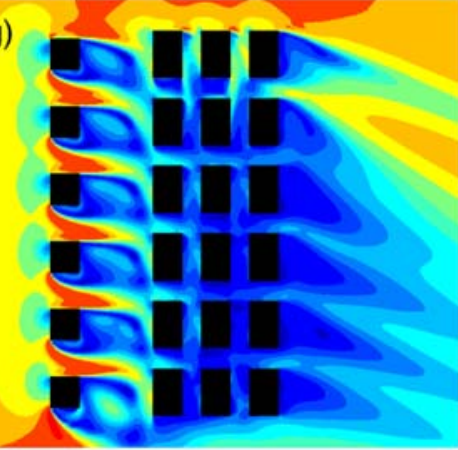

(h)
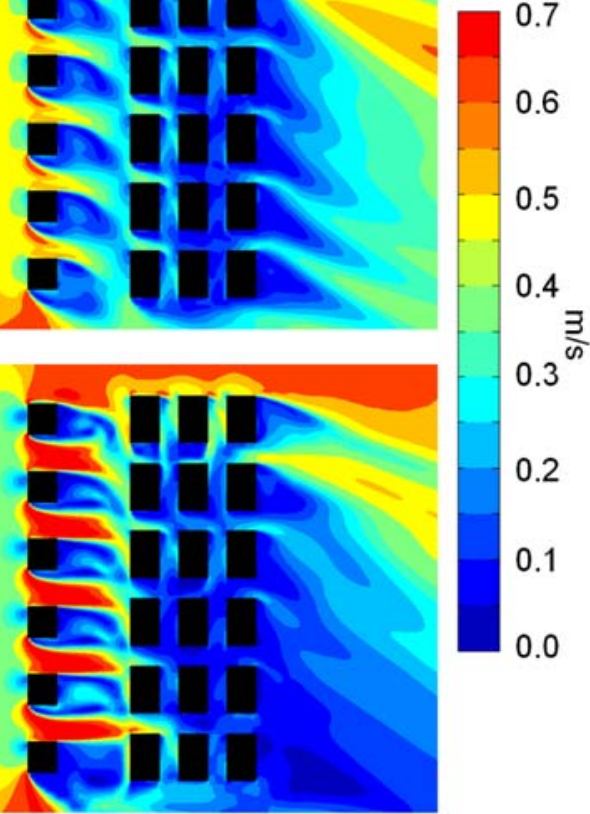

0.4 $0.3^{\frac{3}{5}}$ .2 0.1

Figure 12 Velocity ratio $V R_{w}$ at pedestrian level (2m above ground) in (a) control case, (b) case $H$, (c) case $2 H$ and (d) case $4 H$ and column average (up to 20m) $V_{c}$ in (e) control case, (f) case $H$, (g) case $2 H$ and (h) case $4 H$ in Study B ( $\left.\theta_{2}\right)$. 

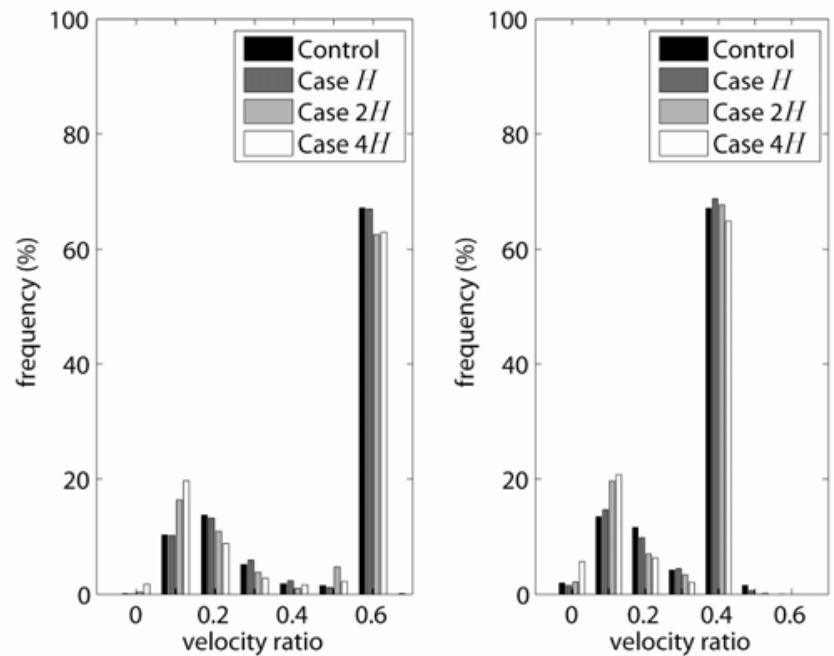

Figure 13 Velocity distribution of different cases (a) in Domain $D$ and (b) at $2 \mathrm{~m}$ above ground in Study A $\left(\theta_{1}\right)$. 


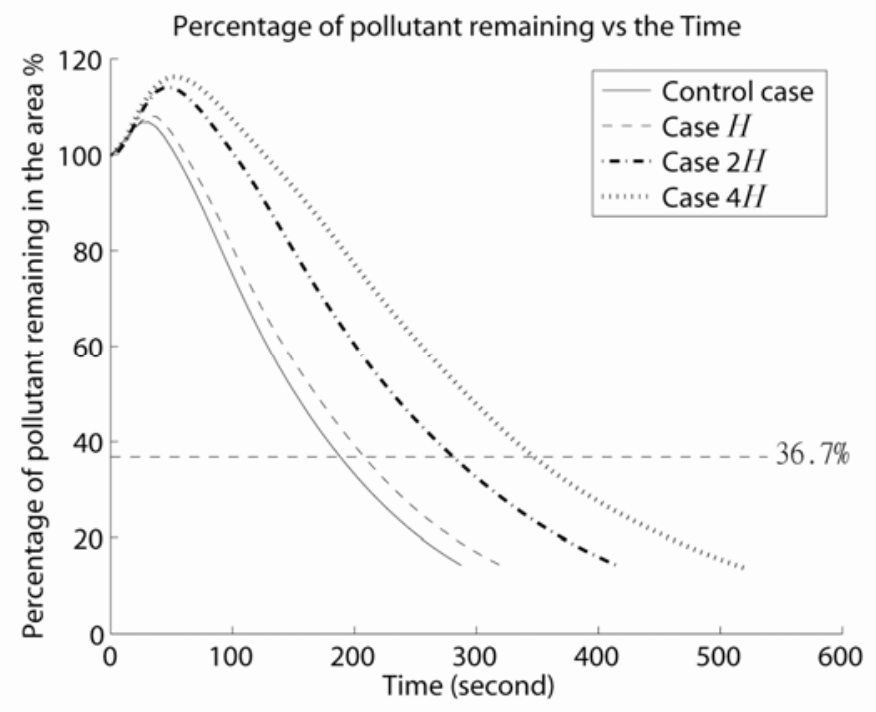

Figure 14 Time series of the percentage of pollutants remaining in $D$ in Study A $\left(\theta_{1}\right)$. 


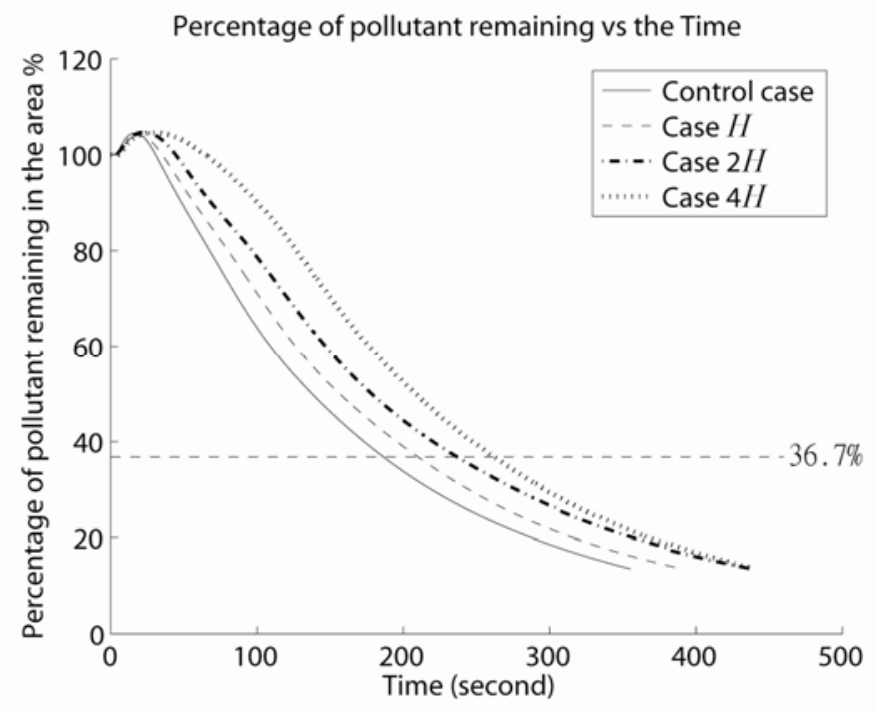

Figure 15 Time series of the percentage of pollutants remaining in $D$ in Study B $\left(\theta_{2}\right)$. 
(a)
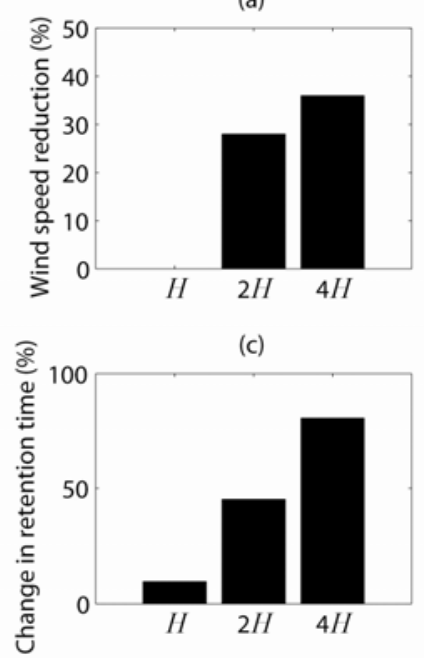

(b)

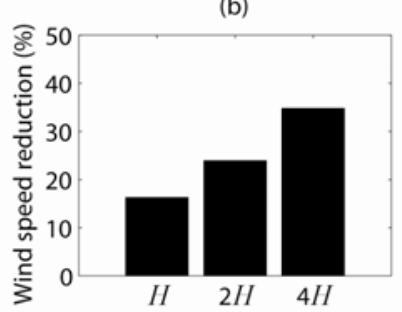

(d)

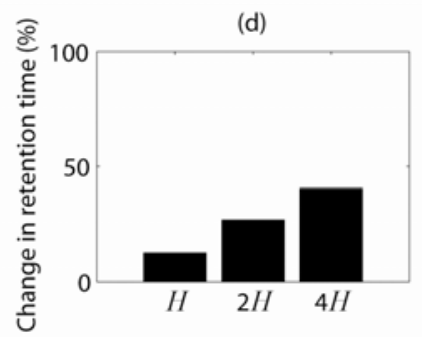

Figure 16 Percentage of wind speed reduction in (a) Study A $\left(\theta_{1}\right)$ and (b) Study $\mathrm{B}\left(\theta_{2}\right)$. Percentage change of retention time in (c) Study A ( $\left.\theta_{1}\right)$ and (d) Study B $\left(\theta_{2}\right)$. 